\title{
SYNTHESIS AND BIOLOGICAL EVALUATION OF SOME NEW PYRIDINES, ISOXAZOLES AND ISOXAZOLOPYRIDAZINES BEARING 1,2,3-TRIAZOLE MOIETY
}

\author{
HUDA R.M. RASHDAN ${ }^{1 *}$, ANHAR ABDEL-AZIEM², DINA H. EL-NAGGAR ${ }^{3}$ \\ and SARA NABIL ${ }^{4}$
}

${ }^{1}$ Chemistry of Natural and Microbial Products Department, Pharmaceutical and Drug Industries Research Division, National Research Centre, Giza, Egypt

${ }^{2}$ Department of Chemistry, Faculty of Science, Al-Azhar University (Girls branch), P.O. box 11754, Youssef Abbas Str., Cairo, Egypt

${ }^{3}$ Department of Applied Organic Chemistry, National Research Centre, Giza, Egypt

${ }^{4}$ Department of Chemistry, College of Science, Imam Abdulrahman Bin Faisal University, p.O. Box 1982, Dammam 31441, Saudi Arabia

\begin{abstract}
Some new isoxazole derivatives 3a-d were synthesized via the reaction of 3-(dimethylamino)-1-(5methyl-1-(3-nitrophenyl)-1H-1,2,3-triazol-4-yl)prop-2-en-1-one (1) with different hydroximoyl chloride derivatives 2a-d. From these new isoxazoles 3a-d a new series of isoxazolopyridazines 4a-d was derived using hydrazine hydrate. In addition, enaminone 1 was reacted with ethyl acetoacetate to afford the corresponding ester derivative $\mathbf{6}$, the latter was submitted to react with different chemical reagents to obtain a variety of bioactive substituted pyridine derivatives. The azido derivative 14, was used as the key molecule for the synthesis of new urea and aryl carbamate derivatives upon its reaction with different amines and phenol through Curtius rearrangement. The chemical compositions of all the new compounds were investigated from their spectral and microanalytical data. The synthesized compounds were tested for their pharmacological potency as, anti-hepatic cancer and anti-microbial agents. Most of the tested compounds showed good anti-hepatic cancer results comparing with the standard drug doxorubicin especially when their toxic effects on the normal cell lines were studied. Referring to the anti-microbial test most of the compounds showed strong effects.
\end{abstract}

Keywords: 1,2,3-Triazoles, Hepatic cancer, Antimicrobial activity, Pyridines, Isoxazoles, Hydroximoyl chlorides, Isoxazolopyridazines, Curtius rearrangement

The emersion of drugs resistance in the disease treatment calls for the continuing investigation of new chemotherapeutic agents with higher activity and lower toxicity able to solve this problem. In the last decade, we have been involved in a program aiming to synthesize functionally substituted heterocycles using cheaply available laboratory starting materials with expected pharmaceutical activity (19). Recently, in the frame of our program, some new functionally substituted pyridines, isoxazoles and their fused derivatives incorporating 1,2,3-triazole moiety were required to be screened for their biological potency as antitumor agents. It seemed to us that the combination of different molecules in one entity may lead to enhanced biological activity owing to the synergistic effect of these rings.
In subsequent investigations, 1,2,3-triazoles were found to be one of the most important nitrogenous heterocyclic systems. Recently, the literature has reported a large number of systems containing 1,2,3-triazole moiety that have been incorporated into a wide spectrum of pharmaceutically and therapeutically interesting drug candidates including, GABA-antagonists (10), synthetic intermediates for antibiotics (11), anti-proliferative agents (12), cytostatic (13), antihistaminic agents (14), muscarinic agonists for the treatment of Alzheimer's disease (15), rotaxanes (16), chemi-luminescent compounds (17), nucleosides(18), virostatics (19), polyheterocyclic compounds with neuroleptic activity (20), aromatase inhibitors (21), c-Met kinase inhibitors (22), antimycobacterial agents (23), 5 $\alpha$-reductase

\footnotetext{
* Corresponding author: e-mail: hudadawoud20@yahoo.com; r.rashdan@nrc.sci.eg
} 
inhibitors (24), antimicrobial agents (25), new inhibitors of HIV type 1 protease (26), antimalarial agents (27) and, glycosidase inhibitors (28), anticancer compound CAI (29), $\beta$-lactum antibiotic Tazobactam, the nucleoside derivative non-nucleoside reverse transcriptase inhibitor known as TSAO (30) and the cephalosporin Cefatrizine (Figure 1).

On the other hand, isoxazoles are found in many natural products as ibotenic acid. They are an important part of a number of drugs, for example, cox-2 inhibitor and nitric oxide donor-furaxan. Isoxazole and pyrazole nucleus blocks are used widely in the pharmaceutical industry $(31,32)$. Their derivatives were mostly utilized with high pharmacology applications, as anti-bacterial, hypoglycemic, anti-inflammatory, analgesic, antiHIV and, anti-cancer agents $(33,34)$. Also, they are used in hypertension, schizophrenia and, Alzheimer disease (35-37). Pyrazoles can be used recently as anti-parasite drugs and kinase inhibitors $(38,39)$.

Moreover, among the most important nitrogencontaining six-member heterocycles, the pyridines or piperidines are mostly found in naturally occurring bioactive compounds like alkaloids (40).

In addition, pyridazines are one of the most important classes of six-membered heterocyclic compounds due to their diverse pharmacological activities. Pharmacologically pyridazines have been found to inhibit the activities of cAMP-PDE-4 and cGMP phosphodiesterase (PDE-3) enzymes (41).

In this paper, we report a new series of potent anti-hepatic cancer agents, through a combination of different bioactive heterocycles.

\section{EXPERIMENTAL}

\section{Instrumentation}

All melting points were determined on an electrothermal apparatus and are uncorrected. IR spectra were recorded ( $\mathrm{KBr}$ discs) on a Shimadzu FT-IR 8201 PC spectrophotometer. ${ }^{1} \mathrm{H}$ NMR and ${ }^{13} \mathrm{C}$ NMR spectra were recorded in $\mathrm{CDCl}_{3}$ and $\left(\mathrm{CD}_{3}\right)_{2} \mathrm{SO}$ solutions on BRUKER 400 FT-NMR system spectrometer and chemical shifts are expressed in ppm units using TMS as an internal reference. Mass spectra were recorded on a GC-MS QP1000 EX Shimadzu. Elemental analyses, anti-microbial were carried out at the Microanalytical Center of Cairo University. Anticancer activity was carried out in the Institute of Cancer, Cairo, Egypt.

\section{3-(Dimethylamino)-1-(5-methyl-1-(3-nitrophen- yl)-1H-1,2,3-triazol-4-yl)prop-2-en-1-one (1)}

A mixture of 1-(5-methyl-1-(3-nitrophenyl)$1 H$-1,2,3-triazol-4-yl)ethanone (2.46 g, $10 \mathrm{mmol})$ and dimethylformamide dimethyl acetal (11.9 g, 14 $\mathrm{mL}, 10 \mathrm{mmol}$ ) were heated under reflux in dry xylene $(15 \mathrm{~mL})$ for $4 \mathrm{~h}$. The hot solution was evaporated to its half volume, then cooled. The resulting solid was collected and crystallized from benzene to give 1 as orange crystals. Yield: 89\%, m.p.: 200$202^{\circ} \mathrm{C}$; FT-IR $\left(\mathrm{KBr}, \mathrm{cm}^{-1}\right): 1665 v(\mathrm{C}=\mathrm{O}), 1620 v$ $(\mathrm{C}=\mathrm{N}), 1585 v(\mathrm{C}=\mathrm{C}) ;{ }^{1} \mathrm{H}$ NMR (400 MHz, DMSO$\left.d_{6}\right): \delta=2.47\left(\mathrm{~s}, 6 \mathrm{H}, 2 \mathrm{CH}_{3}\right), 3.12\left(\mathrm{~s}, 3 \mathrm{H}, \mathrm{CH}_{3}\right) ; 5.12$ $(\mathrm{d}, 1 \mathrm{H}, \mathrm{CH}=), 6.52(\mathrm{~d}, 1 \mathrm{H}, \mathrm{CH}=)$, 7.22-7.51 (m, 4H, Ar'Hs); ${ }^{13} \mathrm{C}$ NMR (100 MHz, DMSO- $\left.d_{6}\right): \delta=15.02$, 22.3, 69, 82, 106, 112.4, 122.6, 130.5, 148.9, 158.6;<smiles>NC(=O)c1nnn(Cc2cc(Cl)c(C(=O)c3ccc(Cl)cc3)c(Cl)c2)c1N</smiles>

CAI<smiles>N[C@@H](C(=O)NC1C(=O)C2C(C(=O)O)=C(CCc3cn[nH]n3)CS[C@H]12)c1ccc(O)cc1</smiles>

Cefatrizine<smiles>O=C(O)[C@H]1[C@@H]2CC(=O)[C@@](O)(O2)[C@H]1Cn1ccnn1</smiles>

Tazobactam

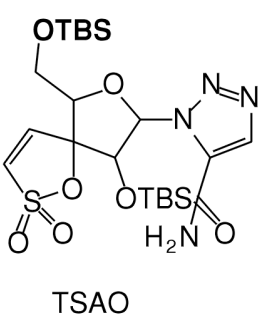

Figure 1. 
Analysis: calcd. for $\mathrm{C}_{14} \mathrm{H}_{15} \mathrm{~N}_{5} \mathrm{O}_{3}(301) \mathrm{C}, 55.81 ; \mathrm{H}$, $5.02 ; \mathrm{N}, 23.24 \%$; found: C, 55.92; H, 4.89; N, $23.19 \%$.

\section{Isoxazole derivatives 3a-d \\ General procedure}

Method A: A mixture of 3-(dimethylamino)-1(5-methyl-1-(3-nitrophenyl)-1H-1,2,3-triazol-4yl)prop-2-en-1-one (1) (3 g, $10 \mathrm{mmol})$, the appropriate hydroximoyl chlorides $\mathbf{2 a - d}(10 \mathrm{mmol})$, and triethylamine $(1.5 \mathrm{~mL}, 1 \mathrm{~g}, 10 \mathrm{mmol})$ in dry toluene $(20 \mathrm{~mL})$ was stirred at $0^{\circ} \mathrm{C}$ for $4 \mathrm{~h}$. The reaction mixture was evaporated under reduced pressure and the product was triturated with petroleum ether 40/60. The resulting solid was collected and crystallized from the proper solvent to give the corresponding isoxazoles 3a-d, respectively.

Method B: A mixture of 1 ( $3 \mathrm{~g}, 10 \mathrm{mmol})$ and the appropriate hydroximoyl chlorides 2 a-d (10 $\mathrm{mmol})$ in dry toluene $(20 \mathrm{~mL})$ containing triethylamine was heated under reflux for $3 \mathrm{~h}$. The solvent was evaporated under reduced pressure and the product was triturated with petroleum ether 40/60. The resulting solid was collected and crystallized from the proper solvent to give the corresponding isoxazoles 3a-d, respectively.

\section{4-(3-Benzoylisoxazol-4-carbonyl)-5-methyl-1-(3- nitrophenyl)-1H-1,2,3-triazole (3a)}

Beige crystals from acetic acid. Yield: 65 $5^{\mathrm{a}}, 74^{\mathrm{b}} \%$, m.p.: $150-152^{\circ} \mathrm{C}$; FT-IR $\left(\mathrm{KBr}, \mathrm{cm}^{-1}\right): 3078$ $v(\mathrm{CH}), 1689 v(\mathrm{C}=\mathrm{O}), 1643 v(\mathrm{C}=\mathrm{N}), 1593 v(\mathrm{C}=\mathrm{C})$; ${ }^{1} \mathrm{H}$ NMR (400 MHz, DMSO- $\left.d_{6}\right): \delta=2.58$ (s, 3H, $\mathrm{CH}_{3}$ ), 7.32-7.85 (m, 9H, ArH's), 8.5 (s, 1H, isoxazole $\mathrm{H}-5) ;{ }^{13} \mathrm{C}$ NMR (100 MHz, DMSO- $\left.d_{6}\right): \delta=$ $10.05,100.25,121.03,124.3,128.9,129.4,129.7$, 132.7, 135.14, 136.07, 145.5, 146.3, 148.7, 154.8; MS (EI, m/z (\%)): $403\left(\mathrm{M}^{+}, 12\right), 401(5), 370(15)$, 362 (22), 359 (5.9), 320(3), 260(6), 240(9), 227 (5), 105 (60), 77 (100), 50(21); Analysis: calcd. for $\mathrm{C}_{20} \mathrm{H}_{13} \mathrm{~N}_{5} \mathrm{O}_{5}$ (403) C, 59.56; H, 3.25; N, 17.36\%; found: C, 59.50; H, 3.13; N, $17.23 \%$.

\footnotetext{
4-[3-(Furan-2-carbonyl)-isoxazol-4-carbonyl]-5methyl-1-(3-nitrophenyl)-1H-1,2,3-triazole (3b)

Brown crystals from benzene. Yield: 58, 72 \% , m.p.: $>300^{\circ} \mathrm{C}$; FT-IR $\left(\mathrm{KBr}, \mathrm{cm}^{-1}\right): 2937,2867$ $v(\mathrm{CH}), 1680 v(\mathrm{C}=\mathrm{O})$; ' $\mathrm{H}$ NMR $(400 \mathrm{MHz}, \mathrm{DMSO}-$ $\left.d_{6}\right): \delta=2.5$ (s, 3H, $\mathrm{CH}_{3}$ ), 7.12-7.48 (m, 7H, ArH's), and $8.32(\mathrm{~s}, 1 \mathrm{H}$, isoxazole $\mathrm{H}-5) ;{ }^{13} \mathrm{C}$ NMR $(100$ $\left.\mathrm{MHz}, \mathrm{DMSO}-d_{6}\right): \delta=7.5,100.25,107.3,124.26$, $128.5,129.07,136.22,145.13,146.12,151.02$, 158.02; MS (EI, m/z (\%)): 395(M+2, 20), $393\left(\mathrm{M}^{+}\right.$, 100), 350 (7), 348 (8), 337 (18), 278 (15), 268 (1),
}

230 (17), 209 (82), 160 (2), 158 (4), 150 (13), 127 (38), 105 (17), 95 (100), 77 (6), 69 (39), 63 (18); Analysis: calcd. for $\mathrm{C}_{18} \mathrm{H}_{11} \mathrm{~N}_{5} \mathrm{O}_{6}$ (393) C, 54.97; H, $2.82 ; \mathrm{N}, 18.81 \%$; found: C, $54.89 ; \mathrm{H}, 2.75 ; \mathrm{N}$, $18.72 \%$.

4-[3-(Thiophen-2-carbonyl)isoxazol-4-carbonyl]5-methyl-1-(3-nitrophenyl)-1H-1,2,3-triazole (3c)

Gray crystals from benzene. Yield: $62^{\mathrm{a}}, 70^{\mathrm{b}} \%$ m.p.: 290-292 ${ }^{\circ}$; FT-IR $\left(\mathrm{KBr}, \mathrm{cm}^{-1}\right): 1687 v(\mathrm{C}=\mathrm{O})$; ${ }^{1} \mathrm{H}$ NMR (400 MHz, DMSO- $\left.d_{6}\right): \delta=2.58(\mathrm{~s}, 3 \mathrm{H}$, $\left.\mathrm{CH}_{3}\right), 7.13-7.58$ (m, 7H, ArH's), and 8.8 (s, $1 \mathrm{H}$, isoxazole H-5); MS(EI, m/z (\%)): $409\left(\mathrm{M}^{+}, 4\right), 390(11)$, 376 (65), 368 (3), 364 (9), 248 (15), 230 (23), 140 (41), 137 (18), 109 (17), 111 (100), 77 (30), 61 (9); Analysis: calcd. for $\mathrm{C}_{18} \mathrm{H}_{11} \mathrm{~N}_{5} \mathrm{O}_{5} \mathrm{~S}$ (409) $\mathrm{C}, 52.81 ; \mathrm{H}$, $2.71 ; \mathrm{N}, 17.11 \%$; found: C, 52.90; H, 2.65; N, $17.3 \%$.

4-[3-(Naphthalen-2-carbonyl)-isoxazol-4-carbonyl]-5-methyl-1-(3-nitrophenyl)-1H-1,2,3-triazole (3d)

Beige crystals from dioxane. Yield: $68^{\mathrm{a}}, 91^{\mathrm{b}} \%$ m.p.:160-162 ${ }^{\circ}$; FT-IR(KBr, $\left.\mathrm{cm}^{-1}\right): 1698 v(\mathrm{C}=\mathrm{O})$, $1622 v(\mathrm{C}=\mathrm{N}), 1590 v(\mathrm{C}=\mathrm{C}) ;{ }^{1} \mathrm{H}$ NMR $(400 \mathrm{MHz}$, DMSO- $\left.d_{6}\right): \delta=2.58\left(\mathrm{~s}, 3 \mathrm{H}, \mathrm{CH}_{3}\right), 7.22-7.78(\mathrm{~m}$, $11 \mathrm{H}$, ArH's), 8.9 (s, 1H, isoxazole H-5); MS (EI, $\mathrm{m} / \mathrm{z}(\%)):$ 453( $\left.\mathrm{M}^{+}, 12\right), 402(50), 390$ (12), 380 (9), 377 (62), 260 (8), 230 (5), 227 (6), 176 (1), 150 (100), 77 (2); Analysis: calcd. for $\mathrm{C}_{24} \mathrm{H}_{15} \mathrm{~N}_{5} \mathrm{O}_{5}$ (453) C, 63.58; H, 3.33; N, 15.45\%; found: C, 63.64; H, $3.22 ; \mathrm{N}, 15.32 \%$.

\section{Isoxazolo[3,4- $d]$ pyridazines 4a-d \\ General procedure}

A mixture of the appropriate isoxazoles 3a-d ( $5 \mathrm{mmol}$ ) and hydrazine hydrate $(1 \mathrm{~g}, 1 \mathrm{~mL}, 10 \mathrm{mmol})$ in ethanol $(20 \mathrm{~mL})$ was heated under reflux for $3 \mathrm{~h}$. The reaction mixture was cooled and the resulting solid was collected and crystallized from the proper solvent to give isoxazolo[3,4- $d]$ pyridazines 4 a-d, respectively.

7-(5-Methyl-1-(3-nitrophenyl)-1H-1,2,3-triazol-4yl)-4-phenylisoxazolo[3,4- $d$ ]-pyridazine (4a)

White crystals from acetic acid. Yield: $85 \%$, m.p.: 292-294 ${ }^{\circ} \mathrm{C}$; FT-IR $\left(\mathrm{KBr}, \mathrm{cm}^{-1}\right): 1620 v(\mathrm{C}=\mathrm{N})$, $1508 v(\mathrm{C}=\mathrm{C}) ;{ }^{1} \mathrm{H}$ NMR $\left(400 \mathrm{MHz}, \mathrm{DMSO}-d_{6}\right): \delta=$ 2.5 (s, 3H, $\mathrm{CH}_{3}$ ), 7.32-7.51 (m, 9H, ArH's), 8.92 (s, $1 \mathrm{H}$, isoxazole $\mathrm{H}-5)$; MS (EI, m/z (\%)): $401\left(\mathrm{M}^{+}, 7\right)$, 390(18), 362(12), 357 (6), 354 (51), 340 (1), 337 (2), 327 (6), 320 (16), 305 (37), 267 (12), 257 (4), 160 (11), 150 (100), 70 (89); Analysis: calcd. for $\mathrm{C}_{20} \mathrm{H}_{13} \mathrm{~N}_{7} \mathrm{O}_{3}$ (401) C, 59.85; H, 3.77; N, 24.43\%; found: C, 59.92; H, 3.65; N, $24.36 \%$. 
4-(Furan-2-yl)-7-(5-methyl-1-(3-nitrophenyl)-1H1,2,3-triazol-4-yl)isoxazolo[3,4- $d$ ]-pyridazine (4b)

Beige crystals from acetic acid. Yield: $90 \%$ m.p.: $250-252^{\circ} \mathrm{C}$; FT-IR $\left(\mathrm{KBr}, \mathrm{cm}^{-1}\right): 1600 v(\mathrm{C}=\mathrm{C})$; ${ }^{1} \mathrm{HNMR}\left(400 \mathrm{MHz}, \mathrm{DMSO}-d_{6}\right): \delta=2.60(\mathrm{~s}, 3 \mathrm{H}$, $\mathrm{CH}_{3}$ ), 7.37-8.11 (m, 7H, ArH's), 8.91 (s, 1H, isoxazole H-5); MS (EI, m/z (\%)): $389\left(\mathrm{M}^{+}, 5\right), 374$ (82), 354 (37), 353 (3), 345 (9), 327 (2), 297 (7), 267 (9), 245 (21), 240 (29), 239 (26), 237 (5), 107 (37), 97 (100), 50 (16); Analysis: calcd. for $\mathrm{C}_{18} \mathrm{H}_{11} \mathrm{~N}_{7} \mathrm{O}_{4}$ (389) C, 55.53; H, 2.85; N, 25.18\%; found: C, 55.62; H, $2.80 ; \mathrm{N}, 25.02 \%$.

7-(5-Methyl-1-(3-nitrophenyl)-1H-1,2,3-triazol-4yl)-4-(thiophen-2-yl)isoxazolo[3,4-d]-pyridazine (4c)

Beige crystals from ethanol. Yield: $91 \%$, m.p.: $>300^{\circ} \mathrm{C}$; FT- IR $\left(\mathrm{KBr}, \mathrm{cm}^{-1}\right): 1602 v(\mathrm{C}=\mathrm{N}), 1509 v$ $(\mathrm{C}=\mathrm{C}) ;{ }^{1} \mathrm{H}$ NMR $\left(400 \mathrm{MHz}, \mathrm{DMSO}-d_{6}\right): \delta=2.57(\mathrm{~s}$, $3 \mathrm{H}, \mathrm{CH}_{3}$ ), 7.13-7.79 (m, 7H, ArH's), 8.95 (s, 1H, isoxazole $\mathrm{H}-5) ;{ }^{13} \mathrm{C}$ NMR (100 MHz, DMSO- $\left.d_{6}\right): \delta=$ $7.35,110.01,121.63,124.05,128.2,129.43$, $134.01,136.8,142.5,144.7,152.3,155.9$; MS (EI, m/z (\%)): 405 (5), 403 (9), 390 (16), 378 (16), 369 (3), 218 (14), 195 (31), 165 (12), 150 (26), 147 (8), 133 (18), 120 (9), 90 (1), 77 (100), 66 (9); Analysis: calcd. for $\mathrm{C}_{18} \mathrm{H}_{11} \mathrm{~N}_{7} \mathrm{O}_{3} \mathrm{~S}$ (405) C, 53.33; H, 2.73; N, 24.19\%; found: C, 53.39; H, 2.65; N, 24.10\%.

7-(5-Methyl-1-(3-nitrophenyl)-1H-1,2,3-triazol-4yl)-4-(naphthalen-6-yl)isoxazolo $[3,4-d]$ pyridazine (4d)

Yellow crystals from acetic acid .Yield: $95 \%$ m.p.: 240-242 ${ }^{\circ} \mathrm{C}$; FT-IR ( $\left.\mathrm{KBr}, \mathrm{cm}^{-1}\right): 1698 v(\mathrm{C}=\mathrm{O})$, $1620 v(\mathrm{C}=\mathrm{N}), 1590 v(\mathrm{C}=\mathrm{C})$; ${ }^{1} \mathrm{H}$ NMR $(400 \mathrm{MHz}$, DMSO- $\left.d_{6}\right): \delta=2.57\left(\mathrm{~s}, 3 \mathrm{H}, \mathrm{CH}_{3}\right), 7.21-8.11(\mathrm{~m}$, $11 \mathrm{H}$, ArH's) ,8.95 (s, 1H, isoxazole H-5); MS (EI, m/z (\%)): $449\left(\mathrm{M}^{+}, 18\right), 448\left(\mathrm{M}^{+}-1,1\right), 435$ (5), 420 (29), 395 (19), 327 (5), 308 (19), 287 (8), 248 (17), 237 (6), 211 (3), 194 (18), 178 (13), 177 (19), 155 (10), 125 (2), 70 (89); Analysis: calcd. for $\mathrm{C}_{24} \mathrm{H}_{15} \mathrm{~N}_{7} \mathrm{O}_{3}$ (449) C, 64.14; H, 3.36; N, 21.82\%; found: C, 64.19; H, 3.25; N, 21.79\%.

Ethyl 2-methyl-6-(5-methyl-1-(3-nitrophenyl)$1 H$-1,2,3-triazol-4-yl)pyridin-3-carboxylate (6)

A mixture of 1 (1.5 g, 5mmol) and ethyl acetoacetate $(0.65 \mathrm{~mL}, 5 \mathrm{mmol})$ in acetic acid $(30 \mathrm{~mL})$ containing ammonium acetate $(0.37 \mathrm{~g}, 5 \mathrm{mmol})$ was refluxed for $4 \mathrm{~h}$. The resulting solid was collected and crystallized to give $\mathbf{6}$ as yellow crystals from acetic acid. Yield (92\%), m.p.: $120-122^{\circ} \mathrm{C}$; FT-IR (KBr, cm $\left.{ }^{1}\right): 1735 v(\mathrm{C}=\mathrm{O}$, ester); ' $\mathrm{H}$ NMR (400 MHz, DMSO$\left.d_{6}\right): \delta=1.22\left(\mathrm{t}, 3 \mathrm{H}, \mathrm{CH}_{2} \mathrm{CH}_{3}\right), 2.58\left(\mathrm{~s}, 3 \mathrm{H}, \mathrm{CH}_{3}\right) .2 .69$ (s, 3H, $\left.\mathrm{CH}_{3}\right), 4.12\left(\mathrm{q}, 2 \mathrm{H}, \mathrm{CH}_{2} \mathrm{CH}_{3}\right), 7.18-7.89(\mathrm{~m}, 6 \mathrm{H}$, ArH's); MS (EI, m/z (\%)): 367 (M+, 18), 352 (14), 337 (11), 323 (5), 269 (14), 250 (9), 197 (26), 177 (29), 150 (100), 127 (17), 105 (2), 103 (2), 77 (80), 66 (19); Analysis: calcd. for $\mathrm{C}_{18} \mathrm{H}_{17} \mathrm{~N}_{5} \mathrm{O}_{4}$ (367) C,58.85; H,4.66; N,19.06\%; found: C, 58.94; H, 4.56; N, 18.97\%.

\section{2-Methyl-6-(5-methyl-1-(3-nitrophenyl)-1H- 1,2,3-triazol-4-yl)pyridin-3-carbohydrazide (7)}

Equimolar amounts of ethyl 2-methyl-6-(5methyl-1-(3-nitrophenyl)-1H-1,2,3-triazol-4yl)pyridin-3-carboxylate (6) and hydrazine hydrate (5 mmol for each) in ethanol $(10 \mathrm{~mL})$ were refluxed for $3 \mathrm{~h}$. The resulting solid, was cooled and crystallized from ethanol to give 7 as white crystals. Yield (79\%), m.p.: $160-162^{\circ} \mathrm{C}$. FT-IR $\left(\mathrm{KBr}, \mathrm{cm}^{-1}\right): 3390 v$ (br., NH, $\left.\mathrm{NH}_{2}\right), 1662 v(\mathrm{C}=\mathrm{O}), 1630 v(\mathrm{C}=\mathrm{N}), 1596 v(\mathrm{C}=\mathrm{C}) ;{ }^{1} \mathrm{H}$ NMR (400 MHz, DMSO- $\left.d_{6}\right): \delta=2.53\left(\mathrm{~s}, 3 \mathrm{H}, \mathrm{CH}_{3}\right.$ ), 2.69 (s, 3H, $\mathrm{CH}_{3}$ ), 5.5 (s, br., $\left.2 \mathrm{H}, \mathrm{NH}_{2}\right), 7.11-7.89$ (m, $6 \mathrm{H}$, ArH's), 8.53(s, 1H, NH); ${ }^{13} \mathrm{C}$ NMR (100 MHz, DMSO- $\left.d_{6}\right): \delta=6.95,18.8,121.6,122.5,124.7,129.3$, 134, 136.5, 138.6, 144.1, 148.05, 153.2, 158.06; MS (EI, m/z (\%)): $354\left(\mathrm{M}^{+}+1,15\right), 353\left(\mathrm{M}^{+}, 14\right), 336(6)$, 322 (45), 277 (12), 250 (6), 217 ( 3), 165 (20), 123 (6), 50 (12), 28 (100); Analysis: calcd. for $\mathrm{C}_{16} \mathrm{H}_{15} \mathrm{~N}_{7} \mathrm{O}_{3}$ (353) C, 54.39; H, 4.28; N, 27.75\%; found: C, 54.45; $\mathrm{H}, 4.15$; N, 27.64\%.

(3,5-Dimethyl-1H-pyrazol-1-yl)(2-methyl-6-(5methyl-1-(3-nityrophenyl)-1H-1,2,3-triazol-4-yl) pyridin-3-yl)methanone (8) and 5-Methyl-2-[2methyl-6-(5-methyl-1-phenyl-1H-1,2,3-triazol-4yl)pyridin-3-carbonyl]-2,4-dihydro-pyrazol-3-one (9)

Equimolar amounts of 2-methyl-6-(5-methyl-1(3-nitrophenyl)-1H-1,2,3-triazol-4-yl)-pyridme-3carbohydrazide (7) and acetylacetone or ethyl acetoacetate $(10 \mathrm{mmol}$ for each) in ethanol $(20 \mathrm{~mL})$ with few drops of acetic acid were refluxed for $2 \mathrm{~h}$. The resulting solid, so formed, was cooled and crystallized from the proper solvent to give the corresponding 8 and $\mathbf{9}$, respectively.

(3,5-Dimethyl-1H-pyrazol-1-yl)(2-methyl-6-(5methyl-1-(3-nitrophenyl)-1H-1,2,3-triazol-4yl)pyridin-3-yl)methanone (8)

White crystals from acetic acid. Yield (85\%), m.p.: $190-192^{\circ} \mathrm{C}$; FT-IR $\left(\mathrm{KBr}, \mathrm{cm}^{-1}\right): 1695 v(\mathrm{C}=\mathrm{O})$, $1589 v(\mathrm{C}=\mathrm{C}) ;{ }^{1} \mathrm{H}$ NMR (400 MHz, DMSO- $\left.d_{6}\right): \delta=$ $2.42\left(\mathrm{~s}, 3 \mathrm{H}, \mathrm{CH}_{3}\right), 2.53\left(\mathrm{~s}, 3 \mathrm{H}, \mathrm{CH}_{3}\right), 2.67$ (s, 3H, $\left.\mathrm{CH}_{3}\right), 2.70\left(\mathrm{~s}, 3 \mathrm{H}, \mathrm{CH}_{3}\right), 6.52(\mathrm{~s}, 1 \mathrm{H}$, pyrazole $\mathrm{H}-4)$, 7.18-7.72 (m, 6 H, ArH's); MS (EI, m/z (\%)): 418 $\left(\mathrm{M}^{+}+1,14\right), 417\left(\mathrm{M}^{+}, 100\right), 402$ (81), 387 (15), 372 (19), 357 (18), 285 (18), 257 (10), 227 (9), 199 (6), 
150 (7), 145 (11), 115 (43), 96 (6); Analysis: calcd. for $\mathrm{C}_{21} \mathrm{H}_{19} \mathrm{~N}_{7} \mathrm{O}_{3}$ (417) C, 60.42; H, 4.59: N, 23.49\%; found: C, 60.35; H,4.65: N, 23.32\%.

5-Methyl-2-[2-methyl-6-(5-methyl-1-(3-nitrophenyl)-1H-1,2,3-triazol-4-yl)-pyridin-3-carbonyl]-2,4-dihydropyrazol-3-one (9)

White crystals from acetic acid. Yield $(80 \%)$, m.p.: $250-252^{\circ} \mathrm{C}$; FT-IR $\left(\mathrm{KBr}, \mathrm{cm}^{-1}\right): 1720,1670 v$ (CO), $1620 v(\mathrm{C}=\mathrm{C}) ;{ }^{1} \mathrm{H}$ NMR (400 MHz, DMSO- $\left.d_{6}\right)$ : $\delta=2.28\left(\mathrm{~s}, 3 \mathrm{H}, \mathrm{CH}_{3}\right), 2.52\left(\mathrm{~s}, 3 \mathrm{H} . \mathrm{CH}_{3}\right), 2.62(\mathrm{~s}, 3 \mathrm{H}$, $\mathrm{CH}_{3}$ ), 3.72 (s, 2H, $\mathrm{CH}_{2}$ (pyrazole)), 7.11-7.79 (m, $6 \mathrm{H}$, ArH's); ${ }^{13} \mathrm{C}$ NMR (100 MHz, DMSO- $\left.d_{6}\right): \delta=7.12$, $18.8,24.5,42.9,121.3,122.5,124.9,129.8,134.2$, 136.1, 138.2, 144, 148.6, 153.1, 159.7, 162; MS (EI, $\mathrm{m} / \mathrm{z}(\%)): 419\left(\mathrm{M}^{+}, 30\right), 417(5), 404(12), 389(5), 285($ 3), 197(7), 153 (6). 135 (10), 105 (100), 95 (8), 77 (29), 69 (15); Analysis: calcd. for $\mathrm{C}_{20} \mathrm{H}_{17} \mathrm{~N}_{7} \mathrm{O}_{4}$ (419) C, 57.28; H, 4.09; N, 23.38\%; found: C, 57.36; H, $3.97 ;$ N, $23.28 \%$.

(4-Arylazo-3,5-dimethylpyrazol-1-yl)-[2-methyl6-(5-methyl-1-(3-nitrophenyl)-1H-1,2,3-triazol-4yl)-pyridin-3-yl]methanone (10) and 4-(Arylhydrazono)-5-methyl-2-[2-methyl-6-(5-methyl-1-(3nitrophenyl)-1H-1,2,3-triazol-4-yl)pyridin-3-carbonyl]-2,4-dihydropyrazol-3-one (11)

Method A: Dropwise addition of arene diazonium chlorides ( $5 \mathrm{mmole}$ ), which is prepared via reaction of the appropriate aniline or $p$-toluidene $(5$ mmole), hydrochloric acid ( $3 \mathrm{~mL}, 6 \mathrm{M})$, and sodium nitrite $(0.37 \mathrm{~g}, 5 \mathrm{mmol})$ at $0-5^{\circ} \mathrm{C}$, to a mixture of the appropriate 8 or $9(5 \mathrm{mmol})$ and sodium acetate trihydrate $(0.66 \mathrm{~g}, 5 \mathrm{mmole})$ in ethanol $(20 \mathrm{~mL})$ at 0 $5^{\circ} \mathrm{C}$, while stirring. The reaction mixture was stirred for $3 \mathrm{~h}$. The resulting solid was collected, washed with water and crystallized to give $\mathbf{1 0 a}, \mathbf{b}$ and $\mathbf{1 1 a}, \mathbf{b}$, respectively.

Method B: A mixture of 7 and the appropriate 3-(2-arylhydrazono)pentane-2,4-dione 12 or ethyl 2arylazo-3-oxo-4-butanoate $\mathbf{1 3}$ (5 mmol for each) in ethanol $(20 \mathrm{~mL})$ and catalytic amount of acetic acid (2-5 drops) was refluxed for $2 \mathrm{~h}$. The resulting solid, so formed, was collected and crystallized from acetic acid to give product identical in all aspects with corresponding products obtained in Method A.

(4-Phenylazo-3,5-dimethylpyrazol-1-yl)[2-methyl-6-(5-methyl-1-(3-nitrophenyl)-1H-1,2,3- triazol-4-yl)pyridin-3-yl]methanone (10a)

Brown crystals from ethanol. Yield (75\%), m.p.: $230-232^{\circ} \mathrm{C}$; FT-IR $\left(\mathrm{KBr}, \mathrm{cm}^{-1}\right): 1710 v(\mathrm{C}=\mathrm{O})$, $1647 v(\mathrm{C}=\mathrm{N}), 1547 v(\mathrm{C}=\mathrm{C})$; ${ }^{1} \mathrm{H}$ NMR $(400 \mathrm{MHz}$, DMSO- $\left.d_{6}\right): \delta=2.29$ (s, 3H, $\left.\mathrm{CH}_{3}\right), 2.37\left(\mathrm{~s}, 3 \mathrm{H}, \mathrm{CH}_{3}\right.$ ), $2.64\left(\mathrm{~s}, 3 \mathrm{H}, \mathrm{CH}_{3}\right) .2 .77$ (s, 3H, $\left.\mathrm{CH}_{3}\right), 7.23-8.14(\mathrm{~m}$, 9 H, ArH's), 8.81 (d, 1H, ArH), 9.17 (d, 1H, ArH); MS (EI, m/z (\%)): $521\left(\mathrm{M}^{+}, 51\right), 506(11), 491(23)$, 476 (15), 430 (17), 422 (1), 377 (17), 365 (17), 350 (7), 312 (27), 277 (35), 237 (37), 191 (15), 181 (3), 165 (100), 120 (14), 70 (7), 43 (39); Analysis: calcd. for $\mathrm{C}_{27} \mathrm{H}_{23} \mathrm{~N}_{9} \mathrm{O}_{3}$ (521) C, 62.18; H, 4.45; N, 24.17\%; found: C, 62.12; H, 4.38; N, $24.11 \%$.

(4-p-Tolylazo-3,5-dimethyl-pyrazol-1-yl)[2methyl-6-(5-methyl-1-(3-nitrophenyl)-1H-1,2,3triazol-4-yl)pyridin-3-yl]methanone (10b)

Brown crystals from acetic acid. Yield (89\%), m.p.: 228-230 ${ }^{\circ} \mathrm{C}$. FT-IR $\left(\mathrm{KBr}, \mathrm{cm}^{-1}\right): 1698 v(\mathrm{C}=\mathrm{O})$, $1622 v(\mathrm{C}=\mathrm{N}), 1590 v(\mathrm{C}=\mathrm{C}) ;{ }^{1} \mathrm{H}$ NMR $(400 \mathrm{MHz}$, DMSO- $\left.d_{6}\right): \delta=2.21\left(\mathrm{~s}, 3 \mathrm{H}, \mathrm{CH}_{3}\right), 2.32\left(\mathrm{~s}, 3 \mathrm{H}, \mathrm{CH}_{3}\right)$, $2.37\left(\mathrm{~s}, 3 \mathrm{H}, \mathrm{CH}_{3}\right), 2.68\left(\mathrm{~s}, 3 \mathrm{H}, \mathrm{CH}_{3}\right), 2.72(\mathrm{~s}, 3 \mathrm{H}$, $\left.\mathrm{CH}_{3}\right), 7.15-7.72(\mathrm{~m}, 8 \mathrm{H}, \mathrm{ArH}$ 's), $8.26(\mathrm{~d}, 1 \mathrm{H}$, ArH's), 9.15 (d, 1H, ArH); ${ }^{13} \mathrm{C}$ NMR (100 MHz, DMSO- $\left.d_{6}\right): \delta=7.1,9.6,12.2,18.4,31.3,104.4$, 107.6, 123.9, 125.7, 128.9, 129, 130.9, 137.6, 138.5, 140, 143.8, 155.3; MS (EI, m/z (\%)): $535\left(\mathrm{M}^{+}, 81\right)$, $534\left(\mathrm{M}^{+}-1,16\right), 520(7), 504(3), 491(12), 456(23)$, 432(15), 420 (17), 396 (2), 370 (10), 309 (9), 290 (11), 277 (17), 257 (15). 225 (17), 170 (19), 156 (5), 145 (27), 127 (19), 123 (4), 117 (28), 97 (5), 96 (48), 77 (72), 60 (99); Analysis: Calcd. for $\mathrm{C}_{28} \mathrm{H}_{25} \mathrm{~N}_{9} \mathrm{O}_{3}$ (535) C, 62.79; H, 4.71; N, 23.54\%; found: C, $62.63 ; \mathrm{H}, 4.82 ; \mathrm{N}, 23.61 \%$.

4-(Phenylhydrazono)-5-methyl-2-[2-methyl-6-(5methyl-1-(3-nitrophenyl)-1H-1,2,3-triazol-4yl)pyridin-3-carbonyl]-2,4-dihydropyrazol-3-one (11a)

Yellowish brown crystals from acetic acid. Yield (64\%), m.p.: $>300^{\circ} \mathrm{C}$; FT-IR $\left(\mathrm{KBr}, \mathrm{cm}^{-1}\right)$ : $3290 v(\mathrm{NH}), 1720,1668 v(\mathrm{C}=\mathrm{O}), 1593 v(\mathrm{C}=\mathrm{C}) ;{ }^{1} \mathrm{H}$ NMR (400 MHz, DMSO- $\left.d_{6}\right): \delta=2.21\left(\mathrm{~s}, 3 \mathrm{H}, \mathrm{CH}_{3}\right)$, $2.64\left(\mathrm{~s}, 3 \mathrm{H}, \mathrm{CH}_{3}\right), 2.71\left(\mathrm{~s}, 3 \mathrm{H}, \mathrm{CH}_{3}\right), 7.10-7.65(\mathrm{~m}$, $11 \mathrm{H}$, ArH's), 11.8 (s, 1H, NH); MS (EI, m/z (\%)): $523\left(\mathrm{M}^{+}, 7\right), 508(19), 493(5), 478$ (4), 450(6), 412(12), 396(3), 365(17), 355 (2), 327 (4), 305 (9), 295 (6), 277 (26), 272 (25), 250 (49), 238 (24), 221 (15), 205 (6), 179 (13), 166 (29), 140 (14), 125 (14), 77 (6), 30 (100); Analysis: calcd. for $\mathrm{C}_{26} \mathrm{H}_{21} \mathrm{~N}_{9} \mathrm{O}_{4}$ (523) C, 59.65; H, 4.04; N, 24.08\%; found: C, $59.76 ; \mathrm{H}, 4.95 ; \mathrm{N}, 23.97 \%$.

4-(p-Tolylhydrazono)-5-methyl-2-[2-methyl-6-(5methyl-1-(3-nitrophenyl)-1H-1,2,3-triazol-4yl)pyridin-3-carbonyl]-2,4-dihydropyrazol-3-one (11b)

Yellow crystals from acetic acid. Yield (72\%). m.p.: 260-262 ${ }^{\circ}$; FT-IR $\left(\mathrm{KBr}, \mathrm{cm}^{-1}\right): 3341 v(\mathrm{NH})$, 
1715, $1663 v(\mathrm{C}=\mathrm{O}), 1602 v(\mathrm{C}=\mathrm{C}) ;{ }^{1} \mathrm{H}$ NMR $(400$ $\left.\mathrm{MHz}, \mathrm{DMSO}-d_{6}\right): \delta=2.22\left(\mathrm{~s}, 3 \mathrm{H}, \mathrm{CH}_{3}\right), 2.37(\mathrm{~s}, 3 \mathrm{H}$, $\left.\mathrm{CH}_{3}\right), 2.65\left(\mathrm{~s}, 3 \mathrm{H}, \mathrm{CH}_{3}\right), 2.75\left(\mathrm{~s}, 3 \mathrm{H}, \mathrm{CH}_{3}\right), 7.11-$ 7.68 (m, 10 H, ArH's), 11.02(s, 1H, NH); MS (EI, $\mathrm{m} / \mathrm{z}(\%)): 539\left(\mathrm{M}^{+}+2.9\right), 537(100), 522(9), 507(13)$, 485(12), 397 (19), 387 (19), 367 (19), 350 (17), 332 (1), 325 (17), 305 (14), 287 (17), 197 (29), 137 (15), 125 (3), 98 (18), 66 (26); Analysis: calcd. for $\mathrm{C}_{27} \mathrm{H}_{23} \mathrm{~N}_{9} \mathrm{O}_{4}$ (537) C. 60.33; H, 4.31; N, 23.45\%; found: C, 60.27 ; $\mathrm{H}, 4.21$ : N, $23.36 \%$.

Azido(2-methyl-6-(5-methyl-1-(3-nitrophenyl)$1 H-1,2,3-$ triazol-4-yl)pyridin-3-yl)-methanone (14)

To a stirred solution of 2-methyl-6-(5-methyl1-(3-nitrophenyl)-1H-1,2,3-triazol-4-yl)-pyridin-3carbohydrazide (7) (5 mmole) in acetic acid $(15 \mathrm{~mL})$ at $0-5^{\circ} \mathrm{C}$, sodium nitrite was added portion-wise till effervescence ended. The reaction mixture was stirred for $2 \mathrm{~h}$. The resulting solid, was collected, filtered, washed with water, and crystallized to give the corresponding 14. Beige crystals, from acetic acid. Yield (86\%), m.p.: $180-184^{\circ} \mathrm{C}$; FT-IR (KBr, $\left.\mathrm{cm}^{-1}\right): 3090 v(\mathrm{CH}), 2137 v$ (azide group) (42), 1687 $v(\mathrm{C}=\mathrm{O}) ;{ }^{1} \mathrm{H}$ NMR $\left(400 \mathrm{MHz}, \mathrm{DMSO}-d_{6}\right): \delta=2.53$ (s, 3H, $\left.\mathrm{CH}_{3}\right), 2.68\left(\mathrm{~s}, 3 \mathrm{H}, \mathrm{CH}_{3}\right), 7.66-8.11(\mathrm{~m}, 6 \mathrm{H}$, ArH's); MS (EI, m/z (\%)): $364\left(\mathrm{M}^{+}, 15\right), 349(11)$, 334(6), 319 (45), 292( 6), 278(14), 264 (16), 257 (45), 245 (10), 227 (19), 197 (18), 177 (22), 165 (12), 105(100), 77 (17), 50 (23); Analysis: calcd. for $\mathrm{C}_{16} \mathrm{H}_{12} \mathrm{~N}_{8} \mathrm{O}_{3}$ (364) C, 52.75; H, 3.32; N, 30.76\%; found: C, 52.66; H, 3.25; N, 30.62\%.

1-(2-Methyl-6-(5-methyl-1-(3-nitrophenyl)-1H1,2,3-triazol-4-yl)pyridin-3-yl)-3-substituted urea 15a-c and 16

A mixture of 14 (1.85 g, $5 \mathrm{mmol})$ and appropriate aniline, $p$-toluidine, $p$-Anisidine or 3-amino5 -phenylpyrazole $(5 \mathrm{mmol})$ in dry dioxane $(20 \mathrm{~mL})$ was refluxed for $4 \mathrm{~h}$. The resulting solid, so formed, was collected and recrystallized to give 15a-c and, 16, respectively.

1-(2-Methyl-6-(5-methyl-1-(3-nitrophenyl)-1H1,2,3-triazol-4-yl)pyridin-3-yl)-3-phenylurea (15a)

Gray crystals, from $N, N$-dimethylformamide. Yield (75\%). m.p.: 243-245 ${ }^{\circ}$; FT-IR $\left(\mathrm{KBr}, \mathrm{cm}^{-1}\right)$ : $3385 v(\mathrm{NH}), 1695 v(\mathrm{C}=\mathrm{O}) ;{ }^{1} \mathrm{H}$ NMR $(400 \mathrm{MHz}$, DMSO- $\left.d_{6}\right): \delta=2.27\left(\mathrm{~s}, 3 \mathrm{H}, \mathrm{CH}_{3}\right), 2.58\left(\mathrm{~s}, 3 \mathrm{H}, \mathrm{CH}_{3}\right)$, 7.62-7.89 (m, $11 \mathrm{H}$, ArH's), 9.25 (s, 2H, 2NH); MS (EI, m/z (\%)): $429\left(\mathrm{M}^{+}, 12\right), 414$ (15), 399(1), 333(19), 276 (23), 237 (35), 137 (1), 91 (100), 77 (18); Analysis: calcd. for $\mathrm{C}_{22} \mathrm{H}_{19} \mathrm{~N}_{7} \mathrm{O}_{3}$ (429) C,
61.53; H, 4.46; N, 22.83\%; found: C, 61.59; H, 6.35; $\mathrm{N}, 22.78 \%$.

1-(2-Methyl-6-(5-methyl-1-(3-nitrophenyl)-1H1,2,3-triazol-4-yl)pyridin-3-yl)-3-p-tolylurea (15b) Off-white crystals, from $N, N$-dimethylformamide, Yield (91\%), m.p.: 260-262 ${ }^{\circ} \mathrm{C}$. FT-IR $\left(\mathrm{KBr}, \mathrm{cm}^{-1}\right): 3306 v(\mathrm{NH}), 1710 v(\mathrm{C}=\mathrm{O}), 1620 v$ $(\mathrm{C}=\mathrm{N}), 1590 v(\mathrm{C}=\mathrm{C})$; ${ }^{1} \mathrm{HNMR}$ (400 MHz, DMSO$\left.d_{6}\right): \delta=2.27\left(\mathrm{~s}, 3 \mathrm{H}, \mathrm{CH}_{3}\right), 2.32\left(\mathrm{~s}, 3 \mathrm{H}, \mathrm{CH}_{3}\right), 2.65(\mathrm{~s}$, $3 \mathrm{H}, \mathrm{CH}_{3}$ ), 7.68-8.21 (m, $10 \mathrm{H}$, ArH's), 9.54 (s, 2H. $2 \mathrm{NH}) ;{ }^{13} \mathrm{C}$ NMR $\left(100 \mathrm{MHz}, \mathrm{DMSO}-d_{6}\right): \delta=9.6$, $16.8,107.02,121.3,123.6,128.3,129.9,133.5$, $135.7,137.5,139.8,141.3,143.9,144.1,146.2$, 152.1; MS (EI, m/z (\%)): $443\left(\mathrm{M}^{+}, 3\right), 328$ (11), 313( 25), 287 (45), 268 (13), 277 (63), 150 (18), 105 (100), 77 (17); Analysis: calcd. for $\mathrm{C}_{23} \mathrm{H}_{21} \mathrm{~N}_{7} \mathrm{O}_{3}$ (443) C, 62.29; H, 4.77; N, 22.11\%; found: C, $62.38 ; \mathrm{H}, 4.72 ; \mathrm{N}, 22.02 \%$.

1-(4-Methoxyphenyl)-3-(2-methyl-6-(5-methyl-1(3-nitrophenyl)-1H-1,2,3-triazol-4-yl)-pyridin-3yl)urea (15c)

Yellow crystals, from $N, N$-dimethylformamide. Yield $(83 \%)$, m.p.: $>300^{\circ} \mathrm{C}$; FT-IR $\left(\mathrm{KBr}, \mathrm{cm}^{-1}\right): 3320$ $v(\mathrm{NH}), 1697 v(\mathrm{C}=\mathrm{O}), 1620 v(\mathrm{C}=\mathrm{N}), 1605 v(\mathrm{C}=\mathrm{C})$; ${ }^{1} \mathrm{H}$ NMR (400 MHz, DMSO- $\left.d_{6}\right): \delta=2.22$ (s, 3H, $\left.\mathrm{CH}_{3}\right), 2.46\left(\mathrm{~s}, 3 \mathrm{H}, \mathrm{CH}_{3}\right), 3.92\left(\mathrm{~s}, 3 \mathrm{H}, \mathrm{OCH}_{3}\right), 7.14-$ 7.82 (m, 10 H, ArH's), 9.65 (s, 1H, NH), 9.75 (s, 1H. 1NH); MS (EI, m/z (\%)): $459\left(\mathrm{M}^{+}, 18\right), 444(19), 428$ (5), 413 (11), 398 (14), 332 (12), 316 (14), 295 (32), 258 (19), 257 (55), 217 (11), 205 (11), 195 (8), 190 (14), 184 (100), 170 (11), 127(8); Analysis: calcd. for $\mathrm{C}_{23} \mathrm{H}_{21} \mathrm{~N}_{7} \mathrm{O}_{4}(459) \mathrm{C}, 60.12 ; \mathrm{H}, 5.61 ; \mathrm{N}, 21.34 \%$; found: C, 60.22; H, 5.69; N, 21.23\%.

1-(2-Methyl-6-(5-methyl-1-(3-nitrophenyl)-1H1,2,3-triazol-4-yl)pyridine-3-yl)-3-(3-phenyl-1Hpyrazol-5-yl)urea (16)

Yellow crystals, from ethanol. Yield $(85 \%)$, m.p.: 230-232 ${ }^{\circ} \mathrm{C}$; FT-IR $\left(\mathrm{KBr}, \mathrm{cm}^{-1}\right): 3316 v(\mathrm{NH})$, $1693 v(\mathrm{C}=\mathrm{O}) ;{ }^{1} \mathrm{H}$ NMR $\left(400 \mathrm{MHz}, \mathrm{DMSO}-d_{6}\right): \delta=$ $2.42\left(\mathrm{~s}, 3 \mathrm{H}, \mathrm{CH}_{3}\right), 2.58\left(\mathrm{~s}, 3 \mathrm{H}, \mathrm{CH}_{3}\right), 6.63(\mathrm{~s}, 1 \mathrm{H}$, pyrazole H-4), 7.18-7.99 (m, $11 \mathrm{H}$, ArH's), 8.95 (s, $1 \mathrm{H}, 1 \mathrm{NH}), 9.58(\mathrm{~s}, 2 \mathrm{H}, 2 \mathrm{NH}) ;{ }^{13} \mathrm{C}$ NMR $(100 \mathrm{MHz}$, DMSO- $\left.d_{6}\right): \delta=8.9,16.5,87.8,105.8,121.6,122.1$, $123.9,127.5,128.7,129.2,133.05,137,141.4$, 143.2, 144.01, 146.9, 151.8, 153.2; MS (EI, m/z (\%)): $495\left(\mathrm{M}^{+}, 37\right), 480$ (51), 465(12), 399(9), 377 (17), 365 (4), 337(7), 320 (31), 320 (15), 308 (27), 280 (3), 237 (7), 220 (17), 165 (100), 119 (14), 66 (17)57 (11), 50 (36); Analysis: calcd. for $\mathrm{C}_{25} \mathrm{H}_{21} \mathrm{~N}_{9} \mathrm{O}_{3}$ (495) C, 60.60; H, 4.27; N, 25.44\%; found: C,60.78; H, 4.17; N, 25.32\%. 
3-(2-Methyl-6-(5-methyl-1-(3-nitrophenyl)-1H1,2,3-triazol-4-yl)pyridin-3-yl)quinazolin-2,4(1H, 3H)dione (17)

A mixture of $\mathbf{1 4}(1.85 \mathrm{~g}, 5 \mathrm{mmol})$ and appropriate anthranilic acid or methyl anthranilate (5 $\mathrm{mmol})$ in dry dioxane $(20 \mathrm{~mL})$ was refluxed for $4 \mathrm{~h}$. The resulting solid formed, was collected and crystallized to give $\mathbf{1 7}$ as gray crystals, from acetic acid. Yield (87\%), m.p.: $220-222^{\circ} \mathrm{C}$; FT-IR $\left(\mathrm{KBr}, \mathrm{cm}^{-1}\right)$ : $3323 v(\mathrm{NH}), 1668 v(\mathrm{C}=\mathrm{O}), 1587 v(\mathrm{C}=\mathrm{C})$; ${ }^{1} \mathrm{H}$ NMR $\left(400 \mathrm{MHz}, \mathrm{DMSO}-d_{6}\right): \delta=2.37\left(\mathrm{~s}, 3 \mathrm{H}, \mathrm{CH}_{3}\right), 2.52$ (s, 3H, $\mathrm{CH}_{3}$ ), 7.29-8.12 (m, $10 \mathrm{H}$, ArH's), 9.23 (s, 1H. 1NH); MS (EI, m/z (\%)): $455\left(\mathrm{M}^{+}, 71\right), 397$ (19), 382 (90), 207 (24), 198 (20), 177 (25), 108 (20), 90 (23), 77 (26), 60 (12), 55 (9); Analysis: calcd. for $\mathrm{C}_{23} \mathrm{H}_{17} \mathrm{~N}_{7} \mathrm{O}_{4}$ (455) $\mathrm{C}, 60.66 ; \mathrm{H}, 3.76 ; \mathrm{N}$, $21.53 \%$; found: C, 60.78; H, 3.82; N, $21.64 \%$

Phenyl 2-Methyl-6-(5-methyl-1-(3-nitrophenyl)$1 H$-1,2,3-triazol-4-yl)pyridin-3-yl-carbamate (18)

A mixture of $14(1.85 \mathrm{~g}, 5 \mathrm{mmol})$ and phenol $(5 \mathrm{mmol})$ in dry benzene $(20 \mathrm{~mL})$ was refluxed for $4 \mathrm{~h}$. The resulting solid formed was collected and crystallized from dioxane to give $\mathbf{1 8}$ as white crystals, yield (65\%) m.p.: $212-214^{\circ} \mathrm{C}$; FT-IR $\left(\mathrm{KBr}, \mathrm{cm}^{-1}\right)$ : $1672 v(\mathrm{C}=\mathrm{O}), 1621 v(\mathrm{C}=\mathrm{N})$; ${ }^{1} \mathrm{H}$ NMR $(400 \mathrm{MHz}$, DMSO- $\left.d_{6}\right): \delta=2.35\left(\mathrm{~s}, 3 \mathrm{H}, \mathrm{CH}_{3}\right), 2.51\left(\mathrm{~s}, 3 \mathrm{H}, \mathrm{CH}_{3}\right)$, 7.11-8.12 (m, 11H, ArH's), 9.48 (s, 1H, 1NH); MS (EI, m/z (\%)): $430(\mathrm{M}+, 35), 412$ (9), 385 (23), 383 (100), 290 (15), 270 (28), 195 (30), 177 (14), 170 (90), 165 (22), 157 (15), 150 (28), 127 (10), 122 (15); Analysis: calcd. for $\mathrm{C}_{22} \mathrm{H}_{18} \mathrm{~N}_{6} \mathrm{O}_{4}$ (430) C,61.39; $\mathrm{H}, 4.22$; N,19.53\%; found: C, 61.45; H, 4.18; N, $19.45 \%$.

\section{Anti-proliferative Activity Cells}

Cell lines: Hep-G2 (human hepatic cancer) and BALB/3T3 (murine fibroblast) were obtained from American Type Culture Collection (Rockville, Maryland, USA) and maintained in the Institute of Cancer, Cairo, Egypt. HepG2 cells were cultured in Eagle's Minimum Essential Medium (EMEM) supplemented with 10\% FBS; DMEM and RPMI1640 are also alternatives that work well. Aspirate and add fresh culture medium every 2-3 days. HepG2 cell doubling time is $48 \mathrm{~h}$. BALB/3T3 cell line was cultured in DMEM (Gibco, UK) supplemented with $2 \mathrm{mM}$ L-glutamine, $10 \%$ fetal bovine serum (GE Healthcare, Logan, UT, USA). To passage cells, rinse cell monolayer with $1 x$ PBS twice and add prewarmed $\left(37^{\circ} \mathrm{C}\right) 0.05 \%$ Trypsin-EDTA solution to cover the bottom of the flask; incubate for 5-7 $\mathrm{min}$. As cells detach, neutralize the Trypsin by adding $4 \mathrm{x}$ volume of complete growth medium with $10 \%$ FBS and gently suspend the cells by pipetting. To avoid clumping do not agitate the cells by shaking the flask while waiting for detachment. Split cells 1:4 every 3 days or $1: 8$ every 6 days. Cultures should be incubated at $37^{\circ} \mathrm{C}$ in a humidified atmosphere with $5 \% \mathrm{CO}_{2}$.

\section{Compounds}

All compounds were dissolved in DMSO (stock solution $10 \mathrm{mg} / \mathrm{mL}$ ) and subsequently diluted in culture medium to reach the required concentrations (ranging from 100 to $0,1 \mu \mathrm{g} / \mathrm{mL}$ ).

\section{An anti-proliferative assay in vitro}

$24 \mathrm{~h}$ before addition of the tested compounds, the cells were plated in 96-well plates (Sarstedt, Germany) at a density of $1 \times 10^{4}$ cells per well. The assay was performed after $72 \mathrm{~h}$ exposure to varying concentrations of the tested compounds. The in vitro cytotoxic effect of all compounds was examined using the SRB assay.

\section{Cytotoxic test SRB}

The details of this technique were described by Skehan et al. $(43,44)$. The cells were attached to the bottom of plastic wells by fixing them with cold 50\% TCA (trichloroacetic acid, Sigma-Aldrich Chemie GmbH, Steinheim, Germany) on the top of the culture medium in each well. The plates were incubated at $4^{\circ} \mathrm{C}$ for $1 \mathrm{~h}$ and then washed five times with tap water. The cellular material fixed with TCA was stained with $0.4 \%$ sulphorhodamine B (SRB, Sigma-Aldrich Chemie GmbH, Steinheim, Germany) dissolved in $1 \%$ acetic acid for $30 \mathrm{~min}$. Unbound dye was removed by rinsing (five times) in $1 \%$ acetic acid. The protein-bound dye was extracted with $10 \mathrm{mM}$ unbuffered Tris base for determination of the optical density ( $\lambda=540 \mathrm{~nm}$ ) in Synergy H4 multi-mode microplate reader (BioTek Instruments USA).

\section{Antimicrobial activity}

The samples were prepared by dissolving $2 \mathrm{mg}$ in $2 \mathrm{~mL}$ of DMSO and $100 \mu \mathrm{L}$ (containing $100 \mu \mathrm{g}$ ) was used in this test. The antimicrobial activity of different samples was investigated by the agar cup plate method. Four different test microbes namely: Pseudomonas aeruginosa (Gram-negative), Staphylococcus aureus (Gram-positive), Aspergillus niger (fungus) and Candida albicans (yeast) were used. Nutrient agar plates were heavily seeded uniformly with $1 \mathrm{~mL}$ of $10^{5}-10^{6}$ cells $/ \mathrm{mL}$ in case of bacteria and yeast. A Czapek-Dox agar plate seeded by the fungus was used to evaluate the antifungal activities. 
Then a hole was made in media by gel cutter (Cork borer no.4) in a sterile condition. Then, one drop of melted agar was poured into the hole and allowed to solidify to make a base layer. After that specific amount of culture filtrate $(0.1 \mathrm{~mL})$ was poured into the hole. Then plates were kept at low temperature $\left(4^{\circ} \mathrm{C}\right)$ for $2-4 \mathrm{~h}$ to allow maximum diffusion. The plates were then incubated at $37^{\circ} \mathrm{C}$ for $24 \mathrm{~h}$ for bacteria and at $30^{\circ} \mathrm{C}$ for $48 \mathrm{~h}$ in the upright position to allow maximum growth of the organisms. The antimicrobial activity of the test agent was determined by measuring the diameter of zone of inhibition expressed in millimeter $(\mathrm{mm})$. The experiment was carried out more than once and mean of reading was recorded (45).

\section{RESULTS AND DISCUSSION}

\section{Chemistry}

The synthetic procedures adopted for the preparation of the target compounds 1-18 were outlined in Schemes 1-3.

3-(Dimethylamino)-1-(5-methyl-1-(3-nitrophenyl)-1H-1,2,3-triazol-4-yl)prop-2-en-1-one (1) was prepared through the reaction of the previously synthesized 1-(5-methyl-1-(3-nitrophenyl)-1H-1,2, 3-triazol-4-yl)ethanone (5) with dimethylformamide dimethyl acetal in dry xylene (Scheme 1).

Boiling of the enamine 1 with 2-chloro-2(hydroxyimino)-1-phenylethanone $\mathbf{2 a}$ in dry toluene containing triethylamine, gave 4-(3-benzoylisoxazol-4-carbonyl)-5-methyl-1-(3-nitrophenyl) $1 \mathrm{H}$ 1,2,3-triazole (3a), not 4-(3-benzoylisoxazol-5-carbonyl)5-methyl-1-(3-nitrophenyl) $1 H$-1,2,3-triazole 5a based on the spectral data of the obtained prod- uct, where the ${ }^{1} \mathrm{H}$ NMR spectrum of $\mathbf{3 a}$ showed singlet signal at $\delta=8.5 \mathrm{ppm}$, which indicated the formation of isoxazole ring. The structure of $\mathbf{3 a}$ also confirmed through the chemical transformation to $\mathbf{4 a}$ by reaction with hydrazine hydrate.

On the other hand, structure of compound 3a was confirmed via alternative synthetic pathway in which stirring of the enamine $\mathbf{1}$ with $\mathbf{2 a}$ in dry toluene containing catalytic amount of triethylamine at room temperature affords product identical in all aspects (m.p., mixed m.p., IR, NMR, mass spectra) with that obtained from the previous method.

Analogously, 1 was reacted with the appropri-

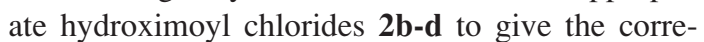
sponding isoxazoles 3b-d, respectively. Refluxing of 3b-d with hydrazine hydrate in boiling ethanol afforded the corresponding isoxazolopyridazines 4b-d (46, 47) (Scheme 1).

Then, enamine 1 was submitted to react with ethyl acetoacetate in boiling acetic acid containing ammonium acetate in the catalytic amount under reflux for $5 \mathrm{~h}$ to give ethyl 2-methyl-6-(5-methyl-1(3-nitrophenyl)-1H-1,2,3-triazole-4-yl)pyridine-3carboxylate (6). The chemical composition of 6 was concluded from its spectral data, where, its IR spectra revealed strong absorption band at $v 1735 \mathrm{~cm}^{-1}$ for the carbonyl ester group, its ${ }^{1} \mathrm{H}$ NMR spectrum revealed triplet signal at $\delta=1.22 \mathrm{ppm}$ and quartet signal at $\delta=4.12 \mathrm{ppm}$ for three protons and two protons of the ester group, respectively. Also, the chemical structure of $\mathbf{6}$ was supported by its mass spectrum which agrees with its molecular formula (see the experimental part). Then, 6 was reacted with hydrazine hydrate to give 2-methyl-6-(5-methyl-1(3-nitrophenyl)-1H-1,2,3-triazole-4-yl)pyridine-3-

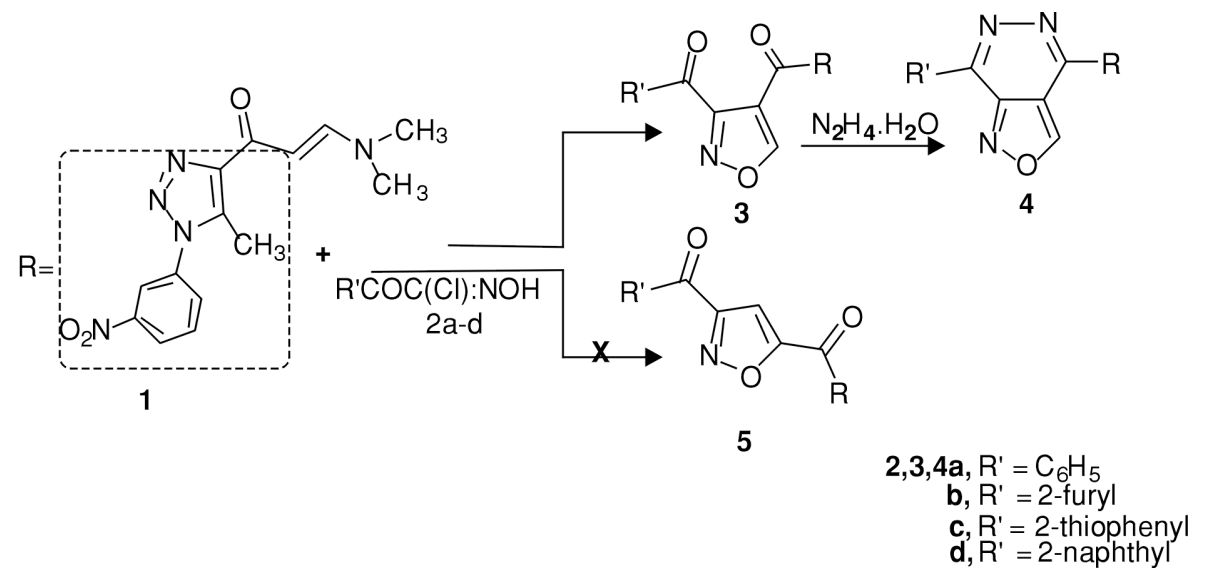

Scheme 1. 


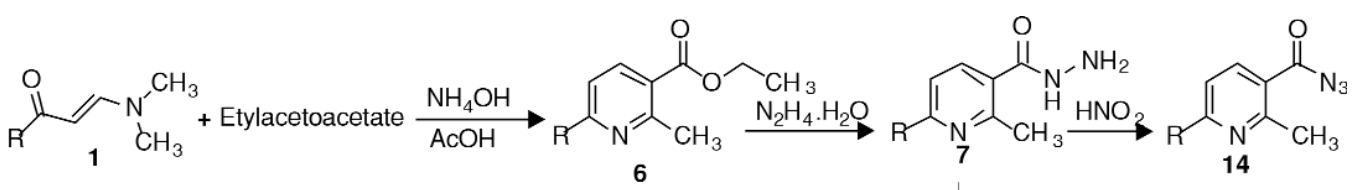

$\mathrm{R}=$ 5-methyl-1-(3-nitrophenyl-1 $\quad H$-1, 2, 3-triazol-4-yl i = Acetylacetone

ii $=$ Ethyl acetoacetate

iii $=\operatorname{ArN}_{2}^{\oplus} \mathrm{Cl}$

10-13 a, $\mathrm{Ar}=\mathrm{C}_{6} \mathrm{H}_{5}$

$\mathrm{b}, \mathrm{Ar}=4-\mathrm{CH}_{3} \mathrm{C}_{6} \mathrm{H}_{4}$

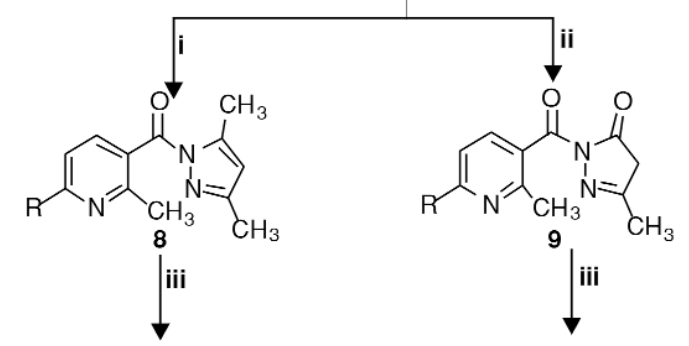

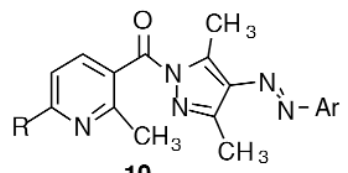

10<smiles></smiles>

12

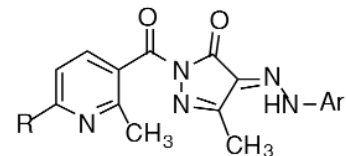

11<smiles>[3H][Al]N=C(C(=O)OCC)C(=O)OC[Te]</smiles>

Scheme 2.<smiles>CNC(=O)Nc1ccc(C)nc1C</smiles>

15a-c<smiles>[R]c1ccc(NC(=O)Nc2cc(-c3ccccc3)[nH]n2)c(C)n1</smiles>

16<smiles>[R]c1ccc(-n2c(=O)[nH]c3ccccc3c2=O)c(C)n1</smiles>

17

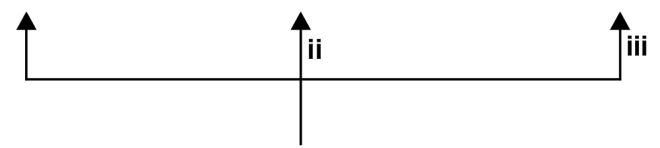

$\mathrm{R}=$ 5-methyl-1-(3-nitrophenyl)-1 H-1,2,3-triazol-4-yl

$\mathbf{i}=$ aniline,$p$-toluidine,$p$-anisidine ii = 3-amino-5-phenylpyrazole

iii $=$ methyl anthranilate

iv $=$ Phenol

15a, $\mathrm{Ar}=\mathrm{C}_{6} \mathrm{H}_{5}$

b, $\mathrm{Ar}=4-\mathrm{CH}_{3} \mathrm{C}_{6} \mathrm{H}_{4}$

c, $\mathrm{Ar}=4-\mathrm{CH}_{3} \mathrm{OC}_{6} \mathrm{H}_{4}$<smiles>[R]c1ccc(C(N)=O)c(C)n1</smiles>

iv<smiles>[R]c1ccc(NC(=O)Oc2ccccc2)c(C)n1</smiles>

Scheme 3. 
carbohydrazide (7). The IR spectrum of 7 showed the disappearance of the absorption band of the carbonyl ester group beside the appearance of a new band at $v 1662 \mathrm{~cm}^{-1}$ for the carbonyl amid group. Also, a strong abroad band appeared at $v 3390 \mathrm{~cm}^{-1}$ for $\mathrm{NH}, \mathrm{NH}_{2}$ groups. ${ }^{1} \mathrm{H}$ NMR spectrum of 7 revealed singlet signal at $\delta=5.5 \mathrm{ppm}$ for $\mathrm{NH}_{2}$ group and singlet signal at $\delta=8.53 \mathrm{ppm}$ for $\mathrm{NH}$ group. Also, the ${ }^{1} \mathrm{H}$ NMR spectra of 7 devoid of any signals for the protons of the ester group which indicated its involvement in the reaction.

The later was submitted to react with acetylacetone and, ethyl acetoacetate to afford (3,5dimethyl-1H-pyrazol-1-yl)(2-methyl-6-(5-methyl-1(3-nitrophenyl)-1H-1,2,3-triazol-4-yl)pyridine-3yl)methanone (8) and 5-methyl-2-[2-methyl-6-(5methyl-1-(3-nitrophenyl)-1H-1,2,3-triazol-4-yl)pyridine-3-carbonyl]-2,4-dihydropyrazol-3-one (9).
Chemical structures of $\mathbf{8}$ and $\mathbf{9}$ were deduced from its spectral data. ${ }^{1} \mathrm{H}$ NMR spectrum of $\mathbf{8}$ revealed the disappearance of any signals for $\mathrm{NH}$ or $\mathrm{NH}_{2}$ groups in addition to the appearance of singlet signal at $\delta=6.52 \mathrm{ppm}$ for $\mathrm{H}-4$ of pyrazole. On the other hand, IR spectrum of compound 9 showed a strong absorption band at $v 1670 \mathrm{~cm}^{-1}$ for the carbonyl of pyrazolone ring. Also, its ${ }^{1} \mathrm{H}$ NMR spectrum showed singled signals at $\delta=3.72 \mathrm{ppm}$ for the two protons of $\mathrm{CH}_{2}$ of pyrazolone ring.

In addition, chemical structures of compounds $\mathbf{8}$ and $\mathbf{9}$ were confirmed via chemical transformation, in which they reacted with arene diazonium chlorides in a cold solution of ethanol in the presence of sodium acetate as a buffer solution to give 10 and 11.

The chemical composition of compounds $\mathbf{1 0}$ and $\mathbf{1 1}$ was confirmed using an alternative synthetic

Table 1. The anti-proliferative potency of the newly prepared derivatives towards hepatic cancer and normal cell lines.

\begin{tabular}{|c|c|c|}
\hline Compound & $\begin{array}{c}\text { Hep-G2 } \\
\mathrm{IC}_{50} \pm \mathrm{SD}[\mu \mathrm{g} / \mathrm{mL}]\end{array}$ & $\begin{array}{c}\text { BALAB } / 3 \mathrm{~T} 3 \\
\mathrm{IC}_{50} \pm \mathrm{SD}[\mu \mathrm{g} / \mathrm{mL}]\end{array}$ \\
\hline Doxorubicin & $3.57 \pm 0.48$ & $3.21 \pm 0.37$ \\
\hline 1 & $\mathrm{Nd}$ & $\mathrm{Nd}$ \\
\hline $3 a$ & $63.32 \pm 11.83$ & $34.09 \pm 12.00$ \\
\hline $3 b$ & $59.20 \pm 9.37$ & $\mathrm{Nd}$ \\
\hline $3 c$ & $53.32 \pm 10.83$ & $\mathrm{Nd}$ \\
\hline $3 d$ & $\mathrm{Nd}$ & $\mathrm{Nd}$ \\
\hline $4 a$ & $\mathrm{Nd}$ & $\mathrm{Nd}$ \\
\hline $4 \mathrm{~b}$ & $37.52 \pm 6.81$ & $\mathrm{Nd}$ \\
\hline $4 c$ & $53.24 \pm 8.65$ & $56.72 \pm 4.14$ \\
\hline $4 d$ & $\mathrm{Nd}$ & $\mathrm{Nd}$ \\
\hline 6 & $11.93 \pm 3.08$ & $\mathrm{Nd}$ \\
\hline 7 & $53.51 \pm 4.48$ & $1.24 \pm 3.01$ \\
\hline 8 & $\mathrm{Nd}$ & $\mathrm{Nd}$ \\
\hline 9 & $42.73 \pm 5.36$ & $28.34 \pm 7.61$ \\
\hline $10 \mathrm{a}$ & $\mathrm{Nd}$ & $\mathrm{Nd}$ \\
\hline $10 \mathrm{~b}$ & $\mathrm{Nd}$ & $\mathrm{Nd}$ \\
\hline $11 \mathrm{a}$ & $32.01 \pm 0.21$ & $2.03 \pm 2.01$ \\
\hline $11 \mathrm{~b}$ & $\mathrm{Nd}$ & $\mathrm{Nd}$ \\
\hline 14 & $\mathrm{Nd}$ & $\mathrm{Nd}$ \\
\hline $15 \mathrm{a}$ & $46.37 \pm 6.17$ & $3.04 \pm 6.02$ \\
\hline $15 b$ & $\mathrm{Nd}$ & $\mathrm{Nd}$ \\
\hline $15 \mathrm{c}$ & $23.14 \pm 5.65$ & $\mathrm{Nd}$ \\
\hline 16 & $78.24 \pm 6.65$ & $23.04 \pm 6.12$ \\
\hline 17 & $61.73 \pm 13.28$ & $63.04 \pm 8.52$ \\
\hline 18 & $15.93 \pm 32.11$ & $4.04 \pm 5.52$ \\
\hline
\end{tabular}


Table 2. Antimicrobial activity of the newly synthesized derivatives against different test microbes.

\begin{tabular}{|c|c|c|c|c|}
\hline \multicolumn{5}{|c|}{ Clear zone $(\mathrm{mm})$} \\
\hline Tested microorganism & Pseudomonas & Staphylococcus & Aspergillus & Candida \\
\hline Sample & aeruginosa & aureus & niger & albicans \\
\hline Neomycin $100 \mu \mathrm{g}$ & 23 & 22 & 0 & 25 \\
\hline Cycloheximide $100 \mu \mathrm{g}$ & 0 & 0 & 35 & 0 \\
\hline 1 & 5 & 0 & 12 & 3 \\
\hline $3 a$ & 15 & 14 & 0 & 10 \\
\hline $3 b$ & 9 & 0 & 20 & 14 \\
\hline $3 c$ & 8 & 20 & 25 & 15 \\
\hline $3 d$ & 14 & 15 & 19 & 15 \\
\hline $4 a$ & 0 & 10 & 18 & 0 \\
\hline $4 \mathrm{~b}$ & 17 & 18 & 29 & 17 \\
\hline $4 \mathrm{c}$ & 12 & 5 & 11 & 21 \\
\hline $4 d$ & 0 & 14 & 0 & 12 \\
\hline 6 & 0 & 10 & 37 & 2 \\
\hline 7 & 5 & 7 & 3 & 4 \\
\hline 8 & 0 & 15 & 8 & 17 \\
\hline 9 & 15 & 2 & 14 & 15 \\
\hline $10 \mathrm{a}$ & 20 & 0 & 25 & 14 \\
\hline $10 \mathrm{~b}$ & 2 & 0 & 27 & 16 \\
\hline $11 \mathrm{a}$ & 11 & 12 & 28 & 10 \\
\hline $11 \mathrm{~b}$ & 5 & 11 & 0 & 9 \\
\hline 14 & 25 & 18 & 13 & 28 \\
\hline $15 \mathrm{a}$ & 4 & 3 & 10 & 15 \\
\hline $15 b$ & 0 & 0 & 2 & 10 \\
\hline $15 \mathrm{c}$ & 23 & 0 & 0 & 10 \\
\hline 16 & 12 & 23 & 15 & 11 \\
\hline 17 & 6 & 2 & 12 & 14 \\
\hline 18 & 17 & 4 & 8 & 0 \\
\hline
\end{tabular}

method and put via refluxing of 7 with the appropriate of 3-(2-arylhydrazono)pentane-2,4-dione $\mathbf{1 2}$ or ethyl 2-arylazo-3-oxo-4-butanoate $\mathbf{1 3}$ in ethanol in the presence of few drops of acetic acid (catalytic amount) yielded products found to be identical to the obtained products of the previous synthetic pathway.

When 7 was allowed to react with nitrous acid it afforded the target (azido(2-methyl-6-(5-methyl1-(3-nitrophenyl) 1H-1,2,3-triazol-4-yl)pyridine-3yl)methanone) (14) (Scheme 2).

Finally, the azido derivative $\mathbf{1 4}$ was utilized as the versatile material for the synthesis of a new series of heterocycles via its reaction with a variety of active reagents via Curtius rearrangement (48).
Compound 14 was submitted to react with different amines as aniline derivatives, 3-amino-5phenylpyrazole and methyl anthranilate in dry dioxane to afford the corresponding urea derivatives 15$\mathbf{1 7}$ in excellent yields. The chemical compositions of the newly synthesized urea derivatives were derived from its spectra. IR spectrum of compound 15a exhibited strong absorption band at $v 3385 \mathrm{~cm}^{-1}$ for the two NH groups and a strong absorption band at $v 1695 \mathrm{~cm}^{-1}$ for carbonyl group. Its ${ }^{1} \mathrm{H}$ NMR spectrum showed singlet signal at $\delta=9.25 \mathrm{ppm}$ for protons of the two NH groups.

Also, $\mathbf{1 4}$ was allowed to react with phenol in dry benzene to afford the phenyl carbamate $\mathbf{1 8}$ (Scheme 3). 


\section{Pharmacology \\ Anti-proliferative activity}

The data calculated as the concentration of the tested samples needed to inhibit half of the cancer cells population $\mathrm{IC}_{50}$ values were calculated for each compound separately and mean values \pm SD are presented in Table 1, the antiproliferative potency of the screened compounds are illustrated in Table 1.

Note: Compounds were tested in concentration from 100 to $0.1 \mu \mathrm{g} / \mathrm{mL}$; Nd: not detected in used concentrations; concentration of DMSO: $1 \%$.

The results stated in Table 1 revealed that many compounds showed good antiproliferative activity against hepatic cancer cell lines (HepG-2) with no toxicity on normal cell lines. These compounds are $\mathbf{3 b}, \mathbf{3 c}, \mathbf{4 b}, \mathbf{6}$ and $\mathbf{1 5 c}$. On the other hand, compounds 7, 11a, 15a, 18 exhibited good antiproliferative activity against the hepatic cancer cell lines (HepG-2) comparing with the standard drug doxorubicin in used range of concentration and they have low toxicity on the normal cell lines.

\section{Antimicrobial activity}

Antibiotics resistance is a serious problem. It has become a global increasingly pressing problem. Around the world, microbes have acquired resistance mechanisms to antibiotic or intrinsically resist antimicrobial drugs and hence the number of patients with diseases which resist these substances continuing to increase (49-51). So, there is a critical demand to investigate new antibiotics.

The newly synthesized derivatives were screened for their in vitro antimicrobial potency on four microbial strains, assigned as Pseudomonas aeruginosa (Gram-negative), Staphylococcus aureus (Gram-positive), Aspergillus niger (fungus) and Candida albicans (yeast). Neomycin was used as a standard antibacterial drug and Cycloheximide was used as a standard antifungal drug to make a comparison between the different effects of the tested newly synthesized derivatives under the same condition. Results found in Table (2) showed the antimicrobial activities of different tested derivatives. From the results it was found that compounds 14 and 15c have antibacterial activity against Pseudomonas aeruginosa exceeding the effect of the Neomycin $(25,23 \mathrm{~mm}$, respectively), referring to the structure-activity relationship (SAR) the azido derivative 14 have pyridine ring in addition to the 1,2,3-triazole ring which may be responsible for the reactivity of this compound. On the other hand, the chemical composition of compound $\mathbf{1 5 c}$ (it has 1,2,3-triazole ring, thiophenyl and isoxazole rings) may be responsible for the high activity of this compound. Compound 16 exhibited strong antibacterial activity against Staphylococcus aureus exceeding the activity of Neomycin $(23 \mathrm{~mm})$, its reactivity may be owing to the combination between different rings (pyrazole, 1,2,3-triazole and pyridine) in the same compound. Strong antifungal activity against Aspergillus niger has been reported with compound $\mathbf{6}$ which has pyridine ring with 1,2,3-triazole ring in addition to ester group in its chemical composition may be the reason for its reactivity. The azido derivative $\mathbf{1 4}$ has been revealed the highest inhibitory effect against Candida albicans.

\section{CONCLUSION}

The newly synthesized derivatives seemed to be preferred for pharmaceutical studies. The results obtained from the tested compounds showed reasonable medical indices especially those of potent activities and this beside their lower possible side effects due to no or weak action on normal cell lines. Compounds 3b, 3c, 4b, 6 and $\mathbf{1 5 c}$ revealed good potency as anti-hepatic cancer compounds with no effect on the normal cells. On the other hand, compounds 7, 11a, 15a, 18 exhibited good anti-proliferative potency against hepatic cancer cell lines with week effect on normal cell lines. As well, compounds $6,14,15 \mathrm{c}, 16$ revealed excellent antimicrobial activities against the tested microorganisms, their activities exceeded the tested standard drugs themselves. Referring to compound $\mathbf{1 4}$ it showed a strong antimicrobial effect against both Pseudomonas aeruginosa and Candida albicans exceeding the effect of Neomycin.

\section{REFERENCES}

1. Abdelhamid A.O., Abdel-Riheem N.A., ElIdreesy T.T., Rashdan H.R.M.: Eur. J. Chem. 3, 322 (2012).

2. El-Hashash M A., Sherif S M., Badawy A A., Rashdan H.R.M.: Der Pharm. Chem. 6, 23 (2014).

3. El-Hashash M.A., Sherif S.M., Badawy A.A., Rashdan H.R.M.: Inter. J. Advanced Res. 2, 900 (2014).

4. El-Hashash M.A., Sherif S.M., Badawy A.A., Rashdan H.R.M.: Inter. J. Advanced Res. 2, 1022 (2014).

5. Rashdan H.R.M., Gomha S.M., El-Gendey M.S., El-Hashash M.A., Soliman A.M.M.: Green Chem. Lett. Rev. 11, 264 (2018).

6. Rashdan H.R.M.: CU Theses (2012). 
7. Rashdan H.R.M., Roaiah H.M., Muhammad Z.A., Wietrzyk J., Milczarek M., Soliman A.M.: Acta Pol. Pharm. 75, 679 (2018).

8. Rashdana H.R.M., Nasrb S.M., El-Refaia H.A., Abdel-Azizc M.S.: JAPS 7, 186 (2017).

9. Abdel-Aziem A., Rashdan H.R.M., Mohamed Ahmed E., Shabaan S.N.: Green Chem. Lett. Rev. 12, 9 (2019).

10. Biagi G., Giorgi I., Livi O., Lucacchini A., Martini C., Scartoni V.: J. Pharm. Sci. 82, 893 (1993).

11. Kume M., Kubota T., Kimura Y., Nakashimizu H., Motokawa K., Nakano M.: J. Antibiotics 46, 177 (1993).

12. Alotaibi F.: Design, synthesis and biological evaluation of novel estradiol-triazole analogs targeting epidermal growth factor receptors in colorectal cancer. South Dakota State University (2017).

13. Shtil A., Gornostaev L., Tsvetkov V., Markova A., Lavrikova T., Khalyavina Y., Kuznetsova A., Kaluzhny D., Shunayev A., Tsvetkova M.: Anticancer Agents Med. Chem. (2017).

14. Vo N.H., Chen S., Che Q., Xie Y.: Thiazole and thiadiazole compounds for inflammation and immune-related uses. Google Patents (2013).

15. Talekar R.R., Wightman R.H.: Tetrahedron 53, 3831 (1997).

16. Chen C-Y., Yang C-H., Hu W-P., Vandavasi J.K., Chung M-I., Wang J-J.: RSC Advances 3, 2710 (2013).

17. Katritzky A.R., Singh S.K.: Journal Org. Chem. 67, 9077 (2002).

18. Pokhodylo N., Savka R., Matiichuk V., Obushak N.: Russ. J. Gen. Chem. 79, 309 (2009).

19. Makabe O., Suzuki H., Umezawa S.: Bull. Chem. Soc. Jpn. 50, 2689 (1977).

20. Filali M.: Scientific Committee of TRAMECH. 24, 5 (2013).

21. Demchuk D.V., Samet A.V., Chernysheva N.B., Ushkarov V.I., Stashina G.A. et al.: Bioorganic Med. Chem. 22, 738 (2014).

22. Nantasenamat C., Worachartcheewan A., Prachayasittikul S., Isarankura-Na-Ayudhya C., Prachayasittikul V.: Eur. J. Med. Chem. 69, 99 (2013).

23. Whiting M., Tripp J.C., Lin Y-C., Lindstrom W., Olson A.J. et al.: J. Med. Chem. 49, 7697 (2006).

24. Gallardo H., Conte G., Bryk F., Lourenço M.C.S., Costa M.S., Ferreira V.F.: J. Braz. Chem. Soc. 18, 1285 (2007).

25. Périon R., Ferrières V., Garcia-Moreno M.I., Mellet C.O., Duval R. et al.: Tetrahedron 61, 9118 (2005).
26. Holla B.S., Mahalinga M., Karthikeyan M.S., Poojary B., Akberali P.M., Kumari N.S.: Eur. J. Med. Chem. 40, 1173 (2005).

27. Soltis M.J., Yeh H.J., Cole K.A., Whittaker N., Wersto R.P., Kohn E.C.: Drug Metab. Dispos. 24, 799 (1996).

28. Manohar S., Khan S.I., Rawat D.S.: Chem. Biol. Drug Des. 78, 124 (2011).

29. Alvarez R., Velazquez S., San-Felix A., Aquaro S., Clercq E.D. et al.: J. Med. Chem. 37, 4185 (1994).

30. Roehri-Stoeckel C., Dangles O., Brouillard R.: Tetrahedron Lett. 38, 1551(1997).

31. Elshemy H.A., Abdelall E.K., Azouz A.A., Moawad A., Ali W.A., Safwat N.M.: Eur. J. Med. Chem. 127, 10 (2017).

32. Narayanan R., Miller D.D., Ponnusamy T., Hwang D-J., He Y.: Selective androgen receptor degrader (sard) ligands and methods of use thereof. Google Patents (2017).

33. Shin K.D., Lee M-Y., Shin D-S., Lee S., Son KH. et al.: J. Biol. Chem. 280, 41439 (2005).

34. Demers J.P., Hageman W.E., Johnson S.G., Klaubert D.H., Look R.A., Moore J.B.: Bioorganic Med. Chem. Lett. 4, 2451 (1994).

35. Rowley M., Broughton H.B., Collins I., Baker R., Emms F. et al.: J. Med. Chem. 39, 1943 (1996).

36. Suresh L., Kumar P.S.V., Onkar P., Srinivas L., Pydisetty Y., Chandramouli G.: Res. Chem. Intermediat. 43, 5433 (2017).

37. Park K-H., Cox L.J.: Tetrahedron Lett. 44, 1067 (2003).

38. Graneto M.J., Kurumbail R.G., Vazquez M.L., Shieh H-S., Pawlitz J.L. et al.: J. Med. Chem. 50, 5712 (2007).

39. Kuettel S., Zambon A., Kaiser M., Brun R., Scapozza L., Perozzo R.: J. Med. Chem. 50, 5833 (2007).

40. Taniguchi T., Ogasawara K.: Org. Lett. 2, 3193 (2000)

41. Van der Mey M., Hatzelmann A., Van der Laan I.J., Sterk G.J., Thibaut U., Timmerman H.: J. Med. Chem. 44, 2511 (2001).

42. Anary-Abbasinejad M., Mosslemin M.H., Hassanabadi A., Tabatabaee M.: Synth. Commun. 38, 3700 (2008).

43. Skehan P., Storeng R., Scudiero D., Monks A., McMahon J. et al.: J. Natl. Cancer Inst. 82, 1107 (1990).

44. Banasiak D., Barnetson A.R., Odell R.A., Mameghan H., Russell P.J.: Radiat. Oncol. Investig. 7, 77 (1999).

45. Barry A.: Principle and Practice, pp. 196-207, Lea \& Febiger, Philadelphia 1976. 
46. Gomha S.M., Zaki Y.H., Abdelhamid A.O.: Molecules 20, 21826 (2015).

47. Abdelhamid A.O., El-Idreesy T.T., Abdelriheem N.A., Dawoud H.R.M.: J. Heterocycl. Chem. 53, 710 (2016).

48. Li J.J.: Name reactions: a collection of detailed mechanisms and synthetic applications, Springer Science \& Business Media (2010).
49. Laxminarayan R., Duse A., Wattal C., Zaidi A.K, Wertheim H.F. et al.: Lancet Infect. Dis. 13, 1057 (2013).

50. Group GARP-IW: Indian J. Med. Res. 134, 281 (2011).

51. Peterson L.: Clin. Microbiol. Infect. 11, 4 (2005).

Received: 30.12 .2018 